\title{
Dynamic Simulation for Risk Analysis: Application to an Exothermic Reaction
}

\author{
Fatine Berdouzi $^{\mathrm{a}}$, Claire Villemur ${ }^{\mathrm{b}}$, Nelly Olivier-Maget ${ }^{\mathrm{a}}$ and Nadine Gabas ${ }^{\mathrm{a}}$ \\ ${ }^{a}$ Laboratoire de Génie Chimique, Université de Toulouse, CNRS, INPT,UPS, 4 allée \\ Emile Monso - CS 84234, F-31432 Toulouse cedex 4, France \\ ${ }^{b}$ INERIS (Institut National de l'Environnement Industriel et des Risques), B.P. 2, 60550 \\ Verneuil-en-Halatte, France
}

\begin{abstract}
Currently, there is a strong demand for quantitative process risk analysis. There is a challenge in describing the process dynamic behaviour in case of failures. We suggest a methodology that combines dynamic simulation (Aspen Plus Dynamics tool), risk analysis (HAZOP review) and risk matrices. The hazardous scenarios leading to major accidents are identified, some of them are simulated which allows the determination of consequences and quantification of severity. Moreover, the knowledge of the process dynamic behaviour and the evolution of the operating parameters during a degraded mode permits adequate safety barriers recommendation. In this paper, the aim is to apply this methodology to a case study concerning an exothermic reaction in a semi-batch reactor. The chosen reaction is the oxidation reaction of sodium thiosulphate by hydrogen peroxide. Advantages and limitations of the proposed approach are revealed and discussed.
\end{abstract}

Keywords: Process safety, Dynamic simulation, Risk assessment, HAZOP method, Runaway scenario.

\section{Introduction}

The risk assessment is a major requirement in the industrial context. Risk identification is essential for ensuring safe design and operation of a process. In chemical industry, chemical reactors involving an exothermic reaction are potentially the most hazardous unit operations (Markos et al., 2005). One major concern is the potential for thermal runaway which can have severe consequences (Stoessel, 2008; Zhang et al., 2014). This scenario has several possible triggers such as cooling loss or wrong reactant concentration (Ni et al., 2016).

In fact, several techniques are available to analyse hazardous scenarios (Marhavilas et al., 2011). Among them, the HAZard and OPerability study (HAZOP) is a well-known technique largely applied (Fuentes-Bargues et al., 2016; Galante et al., 2014; IEC, 2016; ISO 31010, 2010; Kletz, 1999; Saada et al., 2015). Initially, HAZOP was a qualitative method. Since its inception in the 1960's, it has been increasingly used and has evolved to a semi-quantitative method (Trujillo et al., 2015), because risk quantification is decisive for appropriate decision-making. The determination of the effects of failure scenarios is a real challenge (Baybutt, 2015a).

Consequently, there is a real interest in knowing the system behaviour during malfunctions for safety analyses. For this purpose, dynamic simulation is an efficient tool to predict the evolution of variables in chemical processes during deviations from normal 
operating conditions. Several dynamic simulation tools such as Aspen Plus Dynamics, UniSim Design, ProSim Batch are available. Information on system dynamics is valuable, especially for batch and semi-batch reactors, as there are transient operations. For complex and nonlinear systems, it is not straightforward to assess the effects of deviations (Eizenberg et al., 2006a, 2006b). When a deviation from normal operating conditions takes place, knowing the time it takes to approach a threshold value of a critical variable (temperature, pressure...) is important. This enables the characterisation of safety device response times and the most appropriate means to reduce risks. According to Luyben (2012), dynamic simulation allows the investigation of the effects of variable fluctuations on safety response times. The safety response time is defined as the amount of time for a variable to reach critical limits. Luyben (2012) uses dynamic simulation to explore quantitatively safety response time for five different processes. Using Aspen Plus Dynamics he simulated deviations related to heat transfer, such as a loss of cooling or a $50 \%$ drop in the overall heat-transfer coefficient. He collected the time it takes to reach threshold values of variables which permitted the quantitative determination of the transient behaviour of chemical process units.

Other simulations of industrial process plants for safety investigations can be found in the literature (Lou et al., 2006; Luyben, 2002). Combining HAZOP with dynamic simulation can provide the means to investigate and evaluate the scenario consequences. This procedure is applied on an academic case study (Eizenberg et al., 2006a, 2006b), where deviations such as variation in concentration, rise in temperature of the cooling medium etc. are performed. The deviations are computed using MATLAB for a semi-batch reactor where an exothermic oxidation reaction takes place.

The current challenge is to simulate the process degraded modes and especially the propagation of the deviations along the process line. The use of dynamic process simulation has been recently cited by Janosovsky et al. (2017) as a means of having more detailed insight into potential hazard and operability problems. However, in their work, the authors use steady state simulation to simplify the study.

Safety analyses are used to reduce the occurrence of disastrous accidents and/or limit their impacts. Dynamic simulation is a way to predict the system behaviour during critical safety situations. It provides dynamic and quantitative data, essential to insure process safety. As previously suggested, the quantification of deviation effects is one of the challenges faced. A recent study carried out by (Kang and Guo, 2016) is based on deviation cause ranking and classification using sensitivity analysis. The study uses process variable fluctuations to calculate the sensitivity; many scenarios are simulated in order to track critical variable evolutions during abnormal functioning.

Process safety analyses, found in literature, rarely include safety barriers in the dynamic simulations of the deviations. With this in mind, three steps are to be taken:

- combining HAZOP with dynamic simulation for a risk analyses

- using risk matrices

- $\quad$ adding Safety Instrumented Systems

The first step was performed and discussed in a previous work (Berdouzi et al., 2016). The second step uses risk matrices to rank the scenarios based on the risk level. A decision matrix risk-assessment (DMRA) or a "Risk matrix" is used as a tool with two different functions: the first, is ranking and prioritizing risks in order to help decisionmaking, the second is to judge if the risk can be considered as tolerable (ISO 31010, 2010). A risk matrix displays the basic parameters "severity" and "probability" of an event and the notion of risk by means of a graph. The risk levels definition varies, many propositions and recommendations can be found in the literature (Baybutt, 2015b; Duijm, 2015; Lu et al., 2015; Ni et al., 2010). In their paper, Marhavilas et al. (2011) make an 
evaluation of comparative criteria, for various risk analysis and assessment techniques. This highlights that HAZOP and DMRA techniques are complementary in many levels. The quantification helps prioritizing and defining which cases have high critical level.

The third step aims to add Safety Instrumented Systems (SIS) when necessary, in order to reduce the risk level and give new recommendations. Indeed, this literature review highlights the role of dynamic simulation as a tool for improvement of process risk analysis. However, it proves that the identification of possible accidental scenarios and related consequences is still far from being optimal (Jain et al., 2016). Moreover, few studies simulate the actions of safety barriers such as SIS. SIS are the most commonly used methods of reducing the risks associated with major accident hazards in the process (Mkhida et al., 2014). As an example, Vernières-Hassimi and Leveneur (2015) simulated the prevention of thermal runaway by solvent injection. Our methodology permits not only to apprehend and quantify the deviations effects but also to reduce the risk level when necessary. When possible, additional safety barriers can be added to the simulation and validated. This enables to reduce the risk to an acceptable level.

In this paper, the methodology is detailed first of all. Then, the case study, which is the exothermal oxidation reaction of sodium thiosulphate by hydrogen peroxide, is described. Besides, an experiment study of the mixture thermal stability of is shown. The scenarios, put in evidence by the HAZOP method, are analysed and some of them are presented. At last, simulation results are used to rank the scenarios and appreciate the need for additional safety barriers.

\section{Methodology}

The procedure applied in this study is described in Fig. 1. It contains several steps which are described below.

\subsection{Preliminary studies}

First of all, thermokinetic data are required in order to characterize the heat emission and heat capacity of the system. For two-phase systems, the vapour liquid equilibrium is specified and for reactive mixtures, the reaction kinetics are defined.

Thermal stability investigations allow studying the potential decomposition of the compounds and mixtures. Micro calorimeters are used to evaluate the thermal risk of a system when needed. This is necessary to evaluate the hazardous potential and possible thermal runaway.

In addition, a detailed description of the process is made: unit operations, control strategies, time delays etc. Then, operating conditions (temperature, pressure, dosing time etc.) must be examined, especially when exothermal reactions are involved, since the dosing determines the reaction rate. 


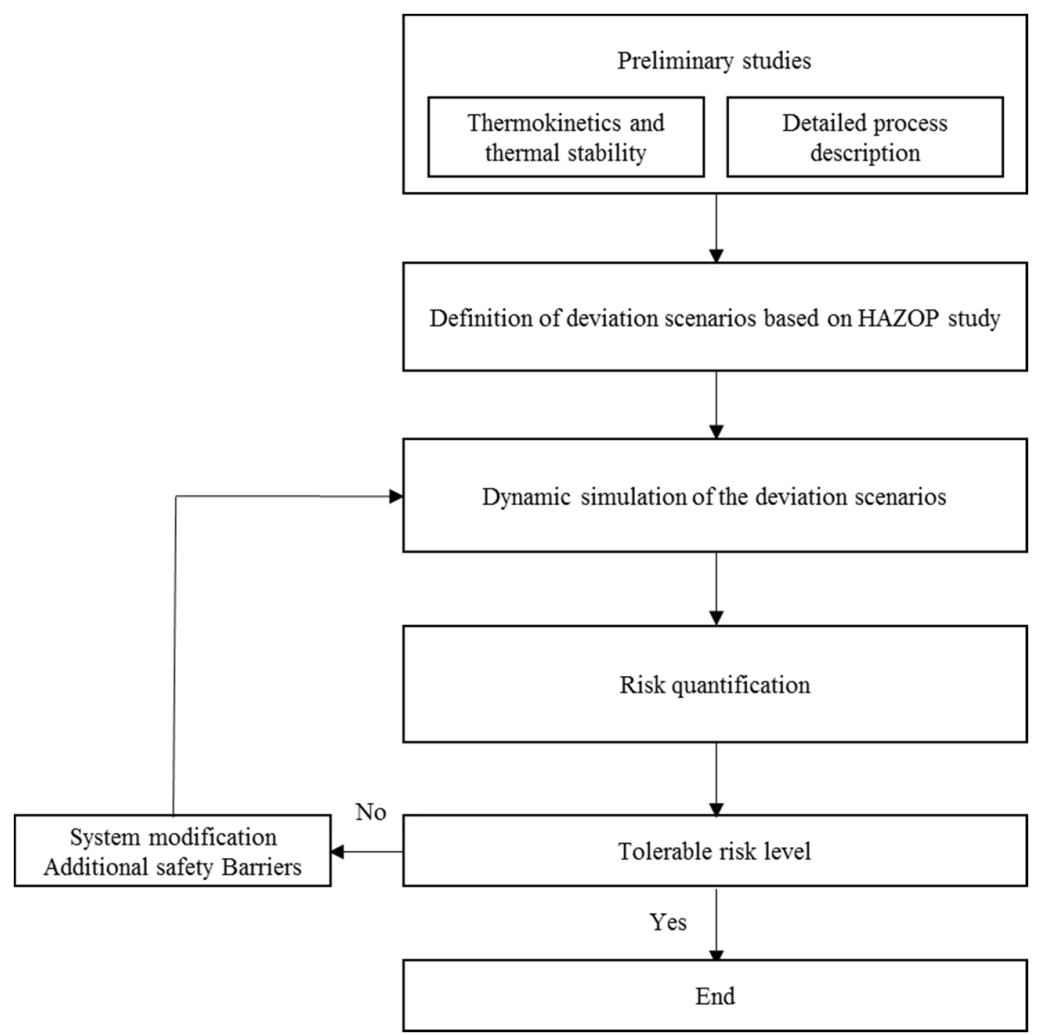

Fig. 1: Methodology description

\subsection{Definition of deviation scenarios based on HAZOP study}

First, HAZOP analysis is carried out, using guide words (more, less, other than etc.) applied to parameters (temperature, pressure, flowrate etc.), in order to ensure that all deviations are considered. For each deviation, the possible causes are listed which helps defining the deviation scenarios properly, specifying the amplitude and duration. Then, the qualitative consequences are put in evidence in order to highlight the scenarios which need to be simulated. These scenarios are converted into numerical scenarios (algorithm of detailed steps to be simulated).

Afterwards, we simulate numerical scenarios using Aspen Plus Dynamics. It allows quantifying the effects (amplitude and rate) and calculating the corresponding risk level for each scenario. To do that, the DMRA technique is used. The ranking of the numerical scenarios is then operated and graphically illustrated in a DMRA matrix. The risk is calculated by multiplying the "probability or likelihood" by the "severity" of an effect.

\subsection{Dynamic simulation of the deviation scenarios}

The dynamic simulation procedure applied includes the following steps (Fig. 2). 


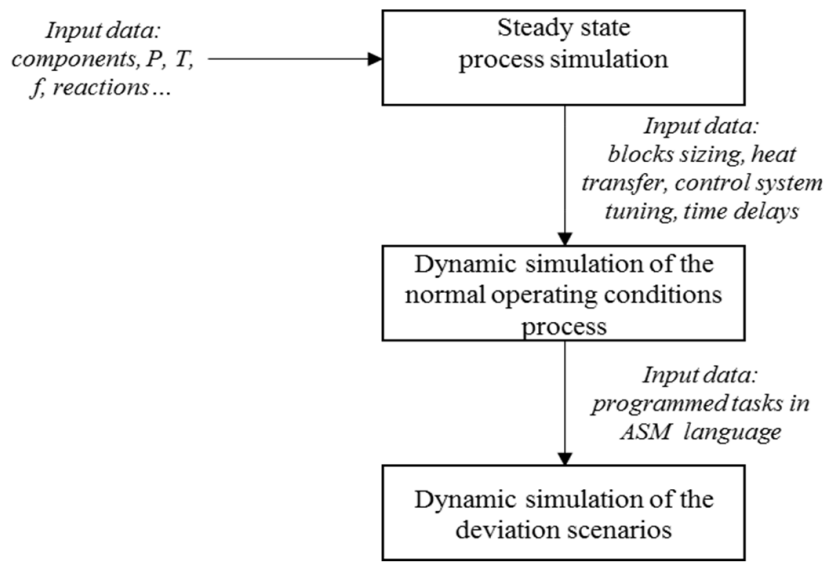

Fig. 2 Simulation procedure

First, the steady state mode of the process is simulated in Aspen Plus environment under normal operating conditions. Input and output flows as well as blocks are used to build the flowsheet. During this step, each block that has a holdup capacity (reactors, valves, mixers etc.) is sized, since dynamic simulation considers accumulation terms in balance equations.

The dynamic model in normal operating conditions is built using Aspen Plus Dynamics (Aspen Plus Dynamics, 2017). Options are investigated, for example, if heattransfer option in the reactor is Logarithmic Mean Temperature Difference "LMTD", it corresponds to having plug flow of coolant through the jacket or internal coil. The temperature driving force is the log-mean average of the temperature differences between the reactor and the inlet and outlet coolant temperatures. The flowrate of the coolant is manipulated in Aspen Plus Dynamics. In our case, the valid phases are "vapour-liquid" and the pressure/flow option is "Pressure driven mode".

Moreover, the programming of events is possible by using VBA and ASM languages (the latter is specific to Aspen software). It allows simulating the different steps of batch or semi-batch reactor mode and the deviation scenarios. Then, the controllers are added and their parameters calculated using Tyreus-Luyben method to find ultimate gain and periods (Luyben, 2002).

The pressure safety valve is sized according to the Design Institute for Emergency Relief Systems (DIERS) methods (Etchells and Wilday, 1998). Afterwards, the study of process deviations, put in evidence by HAZOP method, is operated.

\subsection{Risk quantification}

The evaluation of the fluctuations in the operating parameters allows the quantification of the deviation effects and therefore the system response (dynamics and magnitude). Dynamic simulation is used to determine the time it takes to reach defined threshold values of critical variables such as temperature, pressure and reactant accumulation. This information is valuable since it gives the kinetics of the process behaviour during a deviation. Several defined variable threshold values can be considered. Luyben (Luyben, 2012) suggests different levels of safety constrains and actions in case of deviations. 
In our case, for pressure variations, we propose the three threshold values sketched in Fig. 3 ( $\mathrm{P}_{\mathrm{P}}$ is the process normal pressure and the vessel failure corresponds to the loss of its physical integrity).

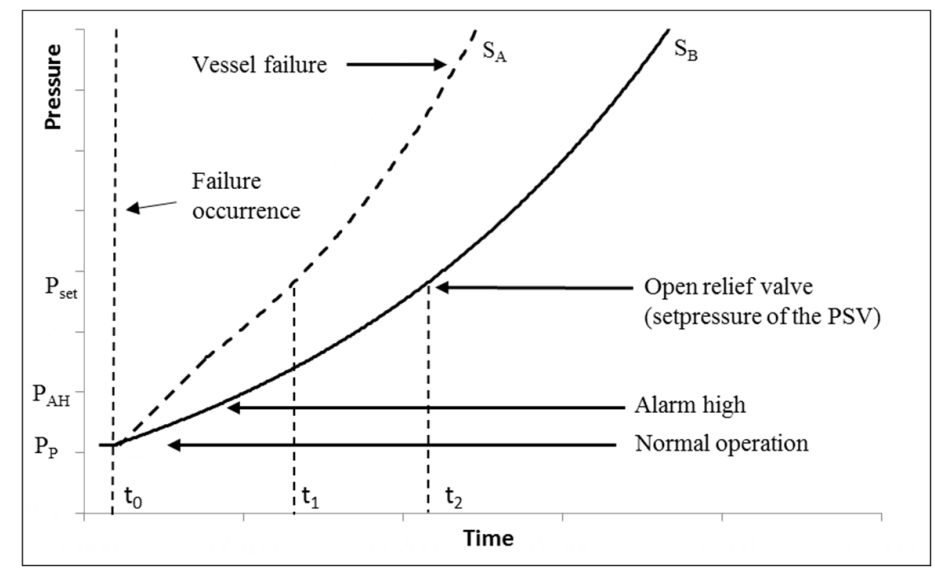

Fig. 3: Pressure threshold values during pressure deviation scenarios

In Fig. 3, the dynamic response during deviation of two hypothetical scenarios $S_{A}$ and $S_{B}$ are represented. A comparative analysis between $S_{A}$ and $S_{B}$ is then possible by examining the response time to reach the $\mathrm{P}_{\text {set }}$ threshold value. The response time is $\Delta t_{P}=t_{1}$ $t_{0}$ for $S_{A}$ and $\Delta t_{P}=t_{2}-t_{0}$ for $S_{B}$. This enables to conclude that $S_{B}$ has a greater response time and is less hazardous than $\mathrm{S}_{\mathrm{A}}$.

Fig. 4 represents threshold values for temperature variations during the occurrence of a deviation ( $\mathrm{T}_{\mathrm{P}}$ is the process normal temperature).

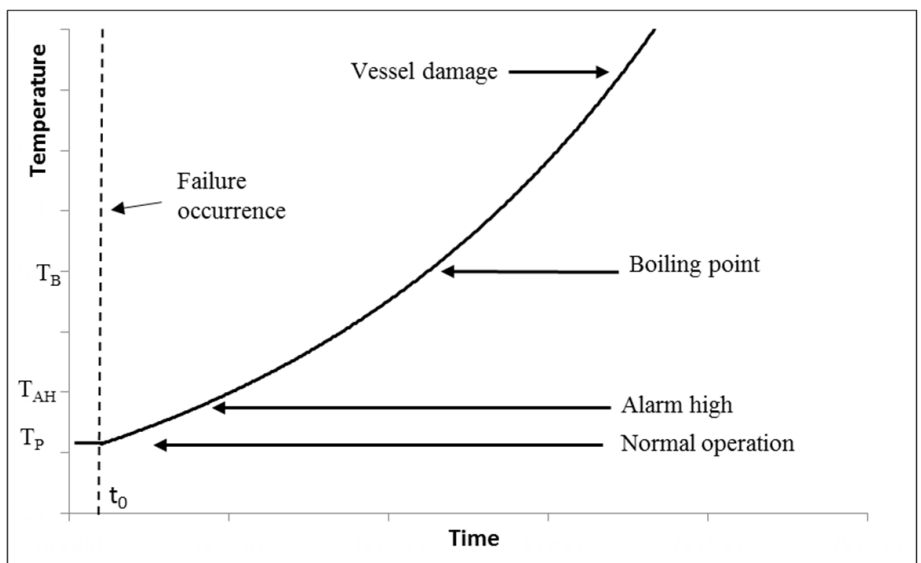

Fig. 4: Temperature threshold values during a temperature deviation scenario 


\subsection{Tolerable risk level}

In order to rank the simulated scenarios, severity and probability criteria are defined for both pressure and temperature. In this perspective, the maximum temperature rise $\Delta \mathrm{T}_{\max }$ is a means to quantify the severity, in terms of temperature, for each deviation. It is a means to apprehend any potential uncontrolled energy release caused by secondary reactions. The variables used to quantify the scenario risk level are listed below:

$$
\begin{gathered}
\Delta T_{\text {inf }}=T_{A_{H}}-T_{P} \\
\Delta T_{\text {sup }}=T_{B}-T_{P}
\end{gathered}
$$

For temperature deviation, three severity levels are set (Table 1). $\Delta \mathrm{t}_{\mathrm{T}}$ is the time duration taken by the system to reach $\Delta \mathrm{T}_{\mathrm{inf}} . \Delta \mathrm{t}_{\mathrm{T}_{\mathrm{inf}}}$ corresponds to the inferior limit and $\Delta \mathrm{t}_{\mathrm{T}_{\text {sup }}}$ corresponds to the superior limit.

Table 1: Severity and probability criteria for temperature deviation

\begin{tabular}{|c|c|c|c|c|}
\cline { 3 - 5 } \multicolumn{2}{c|}{} & \multicolumn{3}{c|}{ Index value } \\
\cline { 3 - 5 } \multicolumn{2}{c|}{ Severity Criteria } & $\Delta \mathrm{T}_{\max }(\mathrm{K})$ & \multicolumn{1}{c|}{2} & 3 \\
\hline Probability Criteria & $\Delta \mathrm{t}_{\mathrm{T}}$ to attain $\Delta \mathrm{T}_{\text {inf }}$ & $>\Delta \mathrm{T}_{\mathrm{inf}}$ & $\Delta \mathrm{T}_{\text {inf }}<\Delta \mathrm{T}_{\max }<\Delta \mathrm{T}_{\text {sup }}$ & $>\Delta \mathrm{T}_{\text {sup }}$ \\
\hline
\end{tabular}

For pressure variations, three severity levels are set. The index scoring and the scale are given in Table 2. Equations (3) and (4) define the limit values of $\Delta \mathrm{P}_{\max }$ used in the scale. $\Delta \mathrm{t}_{\mathrm{P}}$ is the time duration taken to reach the fixed value $\Delta \mathrm{P}_{\text {sup. }} \Delta \mathrm{t}_{\mathrm{P}_{\text {inf }}}$ is the lower bound and $\Delta \mathrm{t}_{\mathrm{P}_{\text {sup }}}$ is the upper bound. According to the obtained value of $\Delta \mathrm{t}_{\mathrm{P}}$, the probability index can be estimated using Table 2 .

$$
\begin{aligned}
& \Delta \mathrm{P}_{\text {inf }}=\mathrm{P}_{\text {AH }}-\mathrm{P}_{\mathrm{P}} \\
& \Delta \mathrm{P}_{\text {sup }}=\mathrm{P}_{\text {set }} \mathrm{P}_{\mathrm{P}}
\end{aligned}
$$

Table 2: Severity and probability criteria for pressure deviation

\begin{tabular}{|c|c|c|c|c|}
\cline { 3 - 5 } \multicolumn{2}{c|}{} & \multicolumn{3}{c|}{ Index value } \\
\cline { 3 - 5 } \multicolumn{2}{c|}{} & 1 & 2 & 3 \\
\hline Severity Criteria & $\Delta \mathrm{P}_{\max }$ (bar) & $\left\langle\Delta \mathrm{P}_{\text {inf }}\right.$ & $\Delta \mathrm{P}_{\text {inf }}<\Delta \mathrm{P}_{\max }<\Delta \mathrm{P}_{\text {sup }}$ & $>\Delta \mathrm{P}_{\text {sup }}$ \\
\hline Probability Criteria & $\Delta \mathrm{t}_{\mathrm{P}}$ to attain $\Delta \mathrm{P}_{\text {sup }}$ & $>\Delta \mathrm{t}_{\mathrm{P}_{\text {sup }}}$ & $\Delta \mathrm{t}_{\mathrm{P}_{\text {inf }}}<\Delta \mathrm{t}_{\mathrm{P}}<\Delta \mathrm{t}_{\mathrm{P}_{\text {sup }}}$ & $<\Delta \mathrm{t}_{\mathrm{P}_{\text {inf }}}$ \\
\hline
\end{tabular}

The index value " 1 " refers to the lowest severity and probability level for both temperature and pressure scales. The risk level is evaluated as explained previously in

\begin{tabular}{|c|c|c|c|c|}
\hline & & \multicolumn{3}{|c|}{ Probability } \\
\hline & & 1 & 2 & 3 \\
\hline \multirow{3}{*}{$\begin{array}{l}\overrightarrow{0} \\
\overrightarrow{0} \\
\vec{\nu} \\
\omega\end{array}$} & 3 & 3 & 6 & $\overline{9}$ \\
\hline & 2 & 2 & 4 & 6 \\
\hline & 1 & 1 & 2 & 3 \\
\hline
\end{tabular}
part 1 (risk=severity x probability). The risk matrix ( risk level (high).

Table 3) includes three zones: acceptable risk level (low), tolerable risk level (medium) and unacceptable risk level (high). 


\section{Case Study}

The previous methodology is applied to the following case study.

\subsection{Description of the chosen reaction}

The reaction examined in this work is the oxidation of sodium thiosulphate $\left(\mathrm{Na}_{2} \mathrm{~S}_{2} \mathrm{O}_{3}\right)$ by hydrogen peroxide $\left(\mathrm{H}_{2} \mathrm{O}_{2}\right)$. This reaction has been previously studied in safety analyses (Benaissa et al., 2008; Benkouider et al., 2012; Chetouani et al., 2003). The stoichiometric scheme is:

$$
2 \mathrm{Na}_{2} \mathrm{~S}_{2} \mathrm{O}_{3}+4 \mathrm{H}_{2} \mathrm{O}_{2} \rightarrow \mathrm{Na}_{2} \mathrm{~S}_{3} \mathrm{O}_{6}+\mathrm{Na}_{2} \mathrm{SO}_{4}+4 \mathrm{H}_{2} \mathrm{O}
$$

This liquid homogeneous reaction is irreversible, fast, and highly exothermic (Lo and Cholette, 1972). The reaction enthalpy is $\Delta \mathrm{Hr}=-586.2 \mathrm{~kJ}^{-\mathrm{mol}^{-1}}\left[\mathrm{Na}_{2} \mathrm{~S}_{2} \mathrm{O}_{3}\right]$. The kinetics can be described by:

$$
\begin{aligned}
& r=k \cdot\left[\mathrm{Na}_{2} \mathrm{~S}_{2} \mathrm{O}_{3}\right] \cdot\left[\mathrm{H}_{2} \mathrm{O}_{2}\right] \text { with } k=k_{0} \cdot \exp \left[\frac{-E_{a}}{R \cdot T}\right] \\
& \mathrm{k}_{0}=2.10^{7} \mathrm{~m}^{3} \cdot \mathrm{mol}^{-1} \cdot \mathrm{s}^{-1} \text { and } \mathrm{E}_{\mathrm{a}}=6.82 \cdot 10^{4} \mathrm{~J} \cdot \mathrm{mol}^{-1} \text {. } \\
& \text { 3.2. Process description }
\end{aligned}
$$

\subsection{Process description}

The process (Fig. 5) consists of a $100 \mathrm{~L}$ standard semi-batch reactor. The tank is filled by two material feeds: the aqueous sodium thiosulphate through the inlet "Stream 1 " and the dosing of aqueous $\mathrm{H}_{2} \mathrm{O}_{2}$ "Stream 2". After the dosing step, the reactor is $80 \%$ full. The nitrogen input "N2" helps maintaining the atmospheric pressure in the reactor. The temperature controllers "TC1" and "TC2" control the reactor temperature, $333.15 \mathrm{~K}$ in normal operating conditions. This system allows the cooling and the heating of the reactor.

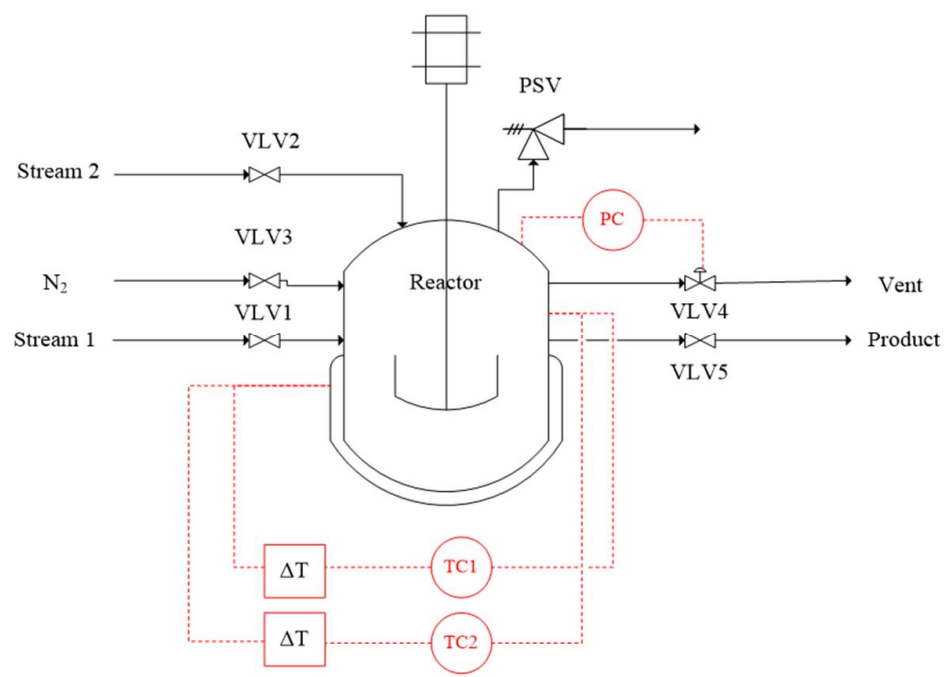

Fig. 5: Fed-batch reactor flowsheet 
There is a valve on each stream: "VLV1" for the Material feed 1, "VLV2" for the Material feed 2, "VLV3" for the nitrogen input, "VLV4" for the vapour phase output "Vent" and "VLV5" for the liquid phase output "Product". Normal operating conditions are summarized in Table 4.

Table 4: Normal operating conditions

\begin{tabular}{|c|c|c|c|}
\cline { 3 - 4 } \multicolumn{2}{c|}{} & Stream 1 & Stream 2 \\
\hline \multirow{3}{*}{ Weight } & $\mathrm{Na}_{2} \mathrm{~S}_{2} \mathrm{O}_{3}$ & $11 \%$ & - \\
\cline { 2 - 4 } percent & $\mathrm{H}_{2} \mathrm{O}_{2}$ & - & $20 \%$ \\
\cline { 2 - 4 } & $\mathrm{H}_{2} \mathrm{O}$ & $89 \%$ & $80 \%$ \\
\hline \multicolumn{2}{|c|}{ Temperature (K) } & 293.15 & 333.15 \\
\hline \multicolumn{2}{|c|}{ Flowrate $\left(\mathrm{L} . h^{-1}\right)$} & 120.9 & 31.2 \\
\hline
\end{tabular}

Kinetic data and normal operating conditions are adopted from Olivier-Maget and Hetreux (2014) work.

\subsection{Protocol description}

The process protocol is illustrated in

Fig. 6. It is composed of several steps:

- feeding of $\mathrm{Na}_{2} \mathrm{~S}_{2} \mathrm{O}_{3}$ (Stream 1) during 20 minutes,

- heating to increase the mixture temperature from $293.15 \mathrm{~K}$ to $333.15 \mathrm{~K}$,

- dosing of $\mathrm{H}_{2} \mathrm{O}_{2}$ (Stream 2) during 60 minutes, at a constant temperature of $333.15 \mathrm{~K}$,

- $\quad$ reaction at constant temperature $(333.15 \mathrm{~K})$; at $\mathrm{t}=204$ minutes we obtain $90 \%$ $\mathrm{Na}_{2} \mathrm{~S}_{2} \mathrm{O}_{3}$ conversion.

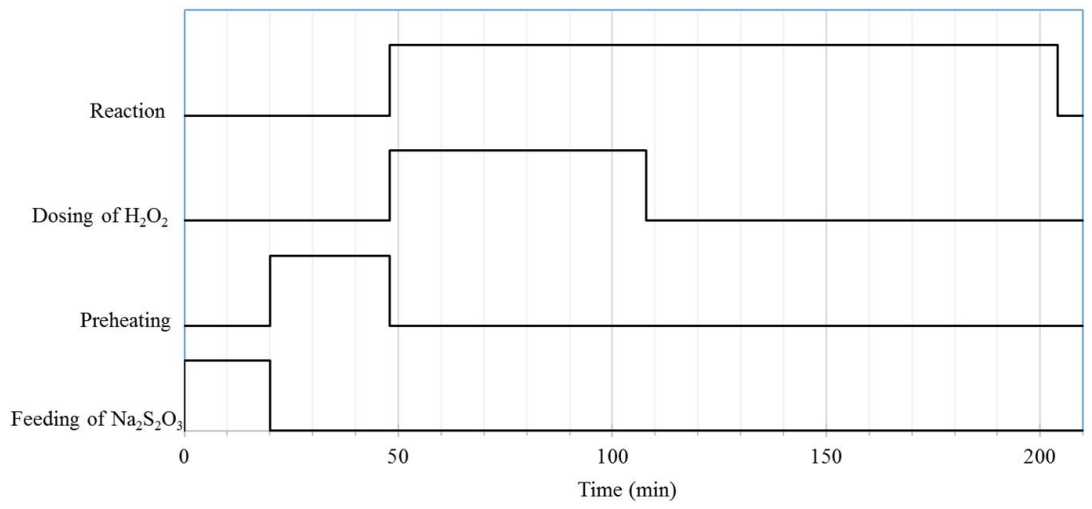

Fig. 6: Process protocol in normal conditions

A PSV is used to evacuate overpressure in the reactor and protect its physical integrity. The Set Pressure $\left(\mathrm{P}_{\mathrm{set}}\right)$ is the relief pressure of the safety valve, which is in compliance with standards (API Standard 520, 2014; API Standard 521, 2014; NF EN ISO 4126, 2016). The PSV is then sized according to the Design Institute for Emergency 
Relief Systems (DIERS) methods. The cooling loss is the considered major scenario for the sizing (Etchells and Wilday, 1998).

\section{Thermokinetics and thermal stability studies}

This part presents the thermodynamic model and investigates the thermal stability of the system. The experiments were conducted in INERIS (Institut National de l'Environnement industriel et des RISques) laboratories.

\subsection{Thermodynamics}

For systems containing polar compounds and operating at relatively low pressure ( $<10$ bars), the thermodynamic model NRTL is suitable. The NRTL model is combined with Henry's law. As the sodium thiosulphate concentration is low (1\% molar fraction), electrolyte complex thermodynamic models are not used.

\subsection{Reaction enthalpy}

The quantification of the reaction enthalpy experimentally is compared with the values found in literature and calculated based on enthalpies of formation of the different chemical compounds. An isothermal calorimeter was used, the C80, which is a device that imposes the temperature on a sample. The C80 calorimeter has the advantage of implementing sample volumes larger than in micro calorimeters. Moreover, it has specific test cells that can mix two products inside the calorimeter and measure the heat flow due to the reaction. This technique was used to put aqueous sodium thiosulfate and aqueous hydrogen peroxide in contact and record the reaction heat released.

The lower compartment of the test cell contains the sodium thiosulfate and water mixture and the upper compartment contains the hydrogen peroxide and water mixture (Table 5). The $\mathrm{C} 80$ test has the same composition as in the studied process.

Table 5: Mass content of $\mathrm{C} 80$ compartments for the enthalpy measurement

\begin{tabular}{lllll}
\hline Weight $(\mathbf{g})$ & $\mathrm{Na}_{2} \mathrm{~S}_{2} \mathrm{O}_{3}$ & $\mathbf{H}_{2} \mathrm{O}_{2} \mathbf{( 3 0 \% )}$ & $\mathbf{H}_{2} \mathrm{O}$ & Total weight \\
\hline Lower compartment & 0.0802 & - & 0.5274 & 0.6076 \\
\hline Upper compartment & - & 0.1209 & 0.1813 & 0.3022 \\
\hline
\end{tabular}

The result of the experiment gives a reaction enthalpy $304 \mathrm{~J} / \mathrm{g}$ (of total the mixture) which corresponds to $599.4 \mathrm{~kJ} / \mathrm{mol}$ of $\mathrm{Na}_{2} \mathrm{~S}_{2} \mathrm{O}_{3}$ at $\mathrm{T}=333 \mathrm{~K}$. It is $2.2 \%$ above the literature value. This may be explained by the decomposition reaction of the excess of hydrogen peroxide.

\subsection{Characteristics of the thermal runaway of the reaction mixture}

All tools used in calorimetry for temperature and pressure measurements can be considered as reactors. These tools permit the screening and the investigation of the possibility of triggering a decomposition reaction, which may lead ultimately to a thermal explosion.

The VSP (Vent Sizing Package) calorimeter was designed in 1985 as Bench Scale Apparatus to characterize runaway chemical reactions. The adiabatic operation allows the temperature and pressure rise rate data to be applied to large-scale process vessels. VSP is a useful tool for measuring temperature and pressure rise rates for thermal analysis and for vent sizing applications. 
The cell is $116 \mathrm{ml}$ and the apparatus measures sample temperature (T1) and pressure (P1) in the cell and external (guard) temperature (T2) and containment vessel pressure (P2). The test cell is surrounded by two heater elements, which are in turn surrounded by thermal insulation material. The function of the inside (test cell) heater is to heat the test sample to a desired temperature and the outside guard heater is regulated to keep an outer aluminium can at the same temperature (T2) as the test cell temperature (T1) which maintains near adiabatic conditions (Leung et al., 2000). For the present experiment, the cell contains sodium thiosulphate and water mixture, which is heated to $333.15 \mathrm{~K}$, at a rate of $2 \mathrm{~K} / \mathrm{min}$. This temperature is then held constant. Then, the hydrogen peroxide is injected into the cell using a syringe. The adiabatic mode is switched on and kept until the $116^{\text {th }}$ minute. The quantities are given in Table 6, T1 and P1 evolutions are illustrated in Fig. 7.

Table 6: VSP test weight quantities

\begin{tabular}{cccc}
\hline Weight $(\mathbf{g})$ & $\mathrm{Na}_{2} \mathbf{S}_{2} \mathrm{O}_{3}$ & $\mathbf{H}_{2} \mathbf{O}_{2} \mathbf{( 3 0 \% )}$ & $\mathbf{H}_{2} \mathbf{O}$ \\
\hline Cell & 4.63 & - & 40.87 \\
\hline Injection & - & 7 & - \\
\hline
\end{tabular}

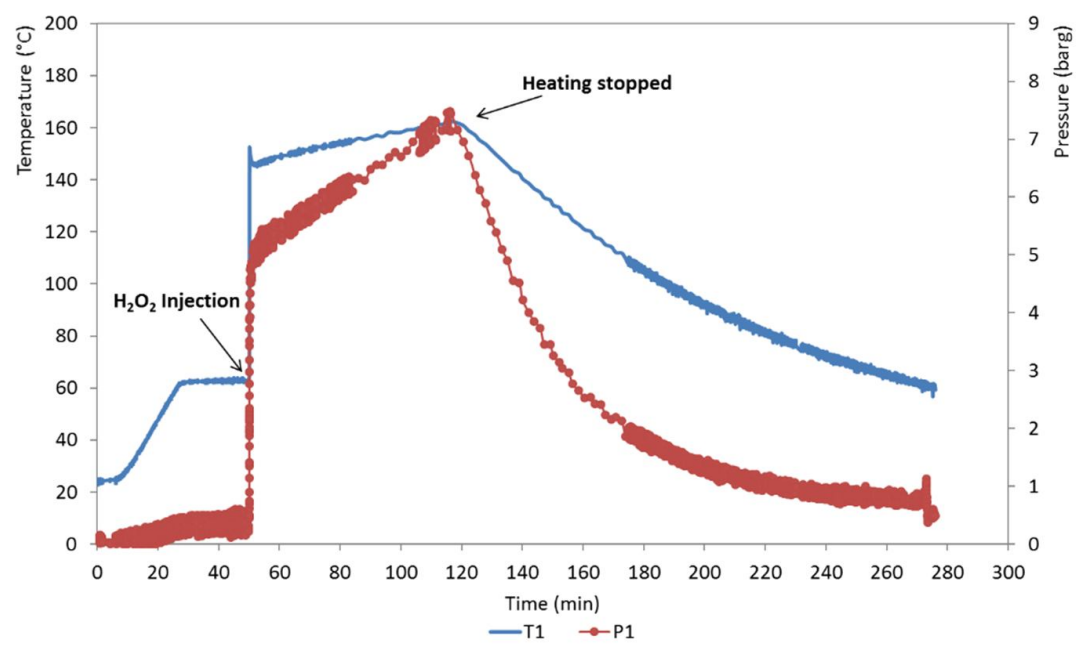

Fig. 7: VSP test results (temperature and relative pressure)

During the injection of hydrogen peroxide, the temperature rises rapidly from $62.5^{\circ} \mathrm{C}$ to Maximum Temperature of Synthesis Reaction (MTSR) of $150.2^{\circ} \mathrm{C}$, which represents an approximate adiabatic temperature rise $\left(\Delta \mathrm{T}_{\mathrm{ad}}\right)$ of $87{ }^{\circ} \mathrm{C}$. The temperature rises along with the pressure. It is noted that there is a slightly higher pressure $(0.35 \mathrm{bar}$ due to incondensable gases) at the end of the experiment, which can be the result of the residual $\mathrm{H}_{2} \mathrm{O}_{2}$ decomposition into water and oxygen. This decomposition reaction is described as follows (European Chemical Industry Coucil CEFIC, 2012):

$\mathrm{H}_{2} \mathrm{O}_{2} \rightarrow 0.5 \mathrm{O}_{2}(\mathrm{~g})+\mathrm{H}_{2} \mathrm{O}(\mathrm{l})$ described by:

The reaction enthalpy is $\Delta \mathrm{Hr} \mathbf{r}^{\prime}=-98 \mathrm{~kJ} \cdot \mathrm{mol}^{-1}$ and the kinetics function is 


$$
\begin{aligned}
& r^{\prime}=k^{\prime} \cdot\left[H_{2} O_{2}\right] \text { with } k^{\prime}=k_{0}^{\prime} \cdot \exp \left[\frac{-E_{a}^{\prime}}{R \cdot T}\right] \\
& k^{\prime}{ }_{0}=1.3510^{5} \mathrm{~m}^{3} \cdot \mathrm{mol}^{-1} \cdot \mathrm{s}^{-1} \text { and } E^{\prime}{ }_{a}=8 \cdot 61 \cdot 10^{4} \mathrm{~J} \cdot \mathrm{mol}^{-1}
\end{aligned}
$$

\subsection{Hydrogen peroxide contamination}

Contamination such as impurities present in the pipes accelerates hydrogen peroxide's decomposition. The presence of $\mathrm{Fe}^{3+}$ in the pipes is common; this is why we choose to study the iron contamination. The coefficient $k_{f}$ is added in the kinetics in equation (9), in case the hydrogen peroxide is contaminated. Error! Reference source not found. gives $k_{f}$ value in case of $\mathrm{Fe}^{3+}$ contamination:

$$
r^{\prime}=k^{\prime} \cdot k_{f} \cdot\left[\mathrm{H}_{2} \mathrm{O}_{2}\right] \text { with } k^{\prime}=k_{0}^{\prime} \cdot \exp \left[\frac{-E_{a}^{\prime}}{R \cdot T}\right]
$$

Table 7: Experimental $\mathrm{k}_{\mathrm{f}}$ value ((European Chemical Industry Coucil CEFIC, 2012)

\begin{tabular}{cc}
\hline Iron content $(\mathbf{m g} / \mathbf{k g})$ & $\boldsymbol{k}_{\boldsymbol{f}}$ \\
\hline 20 & 33360 \\
\hline
\end{tabular}

This decomposition reaction is implemented and defined in the reactions list in Aspen Plus Dynamics simulations.

\section{Risk assessment}

A risk assessment analysis is applied to the case study, in order to define the deviation scenarios and quantify their effects.

\subsection{Deviation scenario definition}

HAZOP analysis is carried out with 24 deviations and their corresponding causes and consequences are listed. The scenarios for which consequences are obviously predictable are eliminated. An example of a highly hazardous scenario is a fire near the reactor. For this scenario all consequences are foreseeable (temperature rise, pressure rise, PSV opening etc.). Only scenarios which consequences are unknown or partially known are simulated.

Table 8 lists the scenarios with uncertain process responses. In normal operation, a conversion of $90 \%$ for sodium thiosulphate is attained at $t=204 \mathrm{~min}$. However, this conversion is expected to be greater for the deviation 4 and lower for the deviation 5 . The dynamic simulation allows the estimation of these values. Note that special attention is paid to the procedural errors leading to deviations, as an example an operator entering an erroneous reactant $\mathrm{B}$ (hydrogen peroxide, $\mathrm{H}_{2} \mathrm{O}_{2}$ ) dosing time. 
Table 8: Definition of candidate deviations for dynamic simulation

\begin{tabular}{|c|c|c|}
\hline Deviations & Hypothetical consequences & $\begin{array}{l}\text { Simulation } \\
\text { scenario }\end{array}$ \\
\hline \multirow[t]{5}{*}{1 No cooling } & 1.1.1 Is there a thermal runaway? & $\mathrm{S} 1$ \\
\hline & 1.2 Clogged cooling water pipe 1.2 .1 same as 1.1 .1 & S1 \\
\hline & $\begin{array}{l}\text { 1.3 Cooling water control valve } 1.2 .1 \text { same as } 1.1 .1 \\
\text { closed }\end{array}$ & $\mathrm{S} 1$ \\
\hline & $\begin{array}{l}\text { 1.4 Guillotine rupture of the } 1.2 .1 \text { same as } 1.1 .1 \\
\text { cooling water pipe }\end{array}$ & S1 \\
\hline & $\begin{array}{l}1.5 \text { Freezing of the cooling } 1.2 .1 \text { same as } 1.1 .1 \\
\text { water }\end{array}$ & S1 \\
\hline 2 Less cooling & $\begin{array}{l}2.1 \text { Error on the temperature } 2.1 .1 \text { same as } 1.1 .1 \\
\text { controller setpoint (more than } \\
333 \mathrm{~K} \text { ) }\end{array}$ & $\mathrm{S} 2, \mathrm{~S} 3, \mathrm{~S} 4$ \\
\hline 3 More cooling & $\begin{array}{l}3.1 \text { Error on the temperature } 3.1 .1 \text { What happens if the temperature } \\
\text { controller setpoint (less than goes back to the normal setpoint } \\
333 \mathrm{~K} \text { ) } \\
\text { temperature of } 333 \mathrm{~K} \text { ? }\end{array}$ & S5 \\
\hline $\begin{array}{l}4 \text { More } \\
\text { concentration } \\
(\text { reactant B) }\end{array}$ & $\begin{array}{l}\text { 4.1 Operator error during the } 4.1 .1 \text { Is the value of the conversion } \\
\text { solution preparation } \\
\qquad \begin{array}{l}\text { rate }>90 \% \text { at } \mathrm{t}=204 \text { min? } \\
\text { decomposition? }\end{array}\end{array}$ & S6, S7 \\
\hline $\begin{array}{l}5 \text { Product } \\
\text { quality }\end{array}$ & $\begin{array}{l}\text { 5.1 Reactant B contamination } 5.1 .1 \text { same as } 1.1 .1 \\
\text { 5.1.3 same as } 4.1 .2 \\
\text { 5.1.4 Does the reaction rate decrease? } \\
5.1 .5 \text { Is the value of the conversion } \\
\text { rate }<90 \% \text { at } \mathrm{t}=204 \mathrm{~min} ?\end{array}$ & S8 \\
\hline
\end{tabular}

The previous step permits detailed systematic deviation scenarios description. Afterwards, the qualitative consequences are studied. The scenarios with high hazard potential and with uncertain process responses are simulated based on corresponding numerical scenarios. The studied numerical scenarios are the following:

- Scenario S1: "More temperature in the reactor due to complete loss of cooling at time corresponding to reactant dosing start ( $\mathrm{t}=48 \mathrm{~min})$ ";

- Scenario S2: "Less cooling in the reactor due to an operator error in the temperature controller set point value (T setpoint $=343 \mathrm{~K}$ at $\mathrm{t}=48 \mathrm{~min}$ )";

- Scenario S3: "Less cooling in the reactor due to an operator error in the temperature controller set point value (T setpoint $=393 \mathrm{~K}$ at $\mathrm{t}=48 \mathrm{~min}$ )";

- Scenario S4: "Less cooling in the reactor due to an operator error in the temperature controller set point value (T setpoint $=873 \mathrm{~K}$ at $\mathrm{t}=48 \mathrm{~min})$ ";

- Scenario S5: "More cooling in the reactor due to an operator error in the temperature controller set point value (T setpoint $=279 \mathrm{~K}$ at $\mathrm{t}=48 \mathrm{~min}$ )";

- $\quad$ Scenario S6: "More concentration of reactant $\mathrm{B}\left(\mathrm{H}_{2} \mathrm{O}_{2}\right)$ due to an operator error during the solution preparation (doubled concentration of reactant $\mathrm{B}$ )";

- $\quad$ Scenario S7: "More concentration of reactant B due to an operator error during the solution preparation (pure reactant B, no dilution)";

- Scenario S8: "Contamination of reactant B by iron cations $\left(\mathrm{Fe}^{3+}\right)$ ".

Moreover, scenarios with two successive deviations are considered for thorough investigations. The chosen scenarios are based on the lessons learned from previous accidents in the industry (French Environment, Energy and the Sea Ministry, 2017). For 
example, accidents related to PSV sizing or abnormal functioning can have grave consequences. Consequently, two scenarios with a cooling loss (S1) and a problem with PSV are studied. Firstly, we consider an undersized PSV and secondly a stuck PSV is considered. The descriptions of these scenarios are the followings:

- $\quad$ Scenario S9: "More temperature in the reactor due to complete loss of cooling at time corresponding to reactant dosing start ( $\mathrm{t}=48 \mathrm{~min})$ and PSV undersized"

- $\quad$ Scenario S10: "More temperature in the reactor due to complete loss of cooling at time corresponding to reactant dosing start $(\mathrm{t}=48 \mathrm{~min})$ and PSV stuck closed". This scenario describes what would happen if the PSV does not open even if the set pressure is attained.

The scenario S5 studies a wrong temperature set point specification by the operator: the mixture temperature is then lower as the normal. In this case, the reactants accumulate inside the reactor. This situation is potentially hazardous, when the temperature is corrected. The greater the accumulation of the reactants, the higher the rate of reaction. S11 corresponds to this scenario:

- Scenario S11: "More cooling in the reactor due to an operator error in the temperature controller set point value $(\mathrm{t}=48 \mathrm{~min})$ and return to normal operating condition temperature of $333 \mathrm{~K}$ at the end of dosing step $(\mathrm{t}=108 \mathrm{~min})$ "

The scenario $\mathrm{S} 8$ considers the contamination of the reactant B by iron in normal process composition. However, when the reactant B is introduced erroneously in high concentration (S8), severe consequences can take place. The following scenario is the combination of scenarios S7 and S8:

- Scenario S12: "More concentration of reactant B (pure reactant B) and contamination of reactant $\mathrm{B}$ (by $\mathrm{Fe}^{3+}$ )" This scenario highlights the effects of a chemical contamination in case the concentration of $\mathrm{H}_{2} \mathrm{O}_{2}$ is abnormally high.

\subsection{Threshold values and dynamic simulation for risk assessment}

Dynamic simulation is used to determine the time it takes to reach threshold values of critical variables such as temperature and pressure. This information is valuable as it describes the kinetics of the process behaviour during a deviation. Several defined parameter threshold values are considered in this case study. The study analyses several failure scenarios and gives the variation rates and profiles of the critical parameters. This shows how fast a variable reaches a threshold value during two different scenarios and compare their kinetics. In order to rank the simulated scenarios based on risk quantification, severity and probability criteria are defined for both pressure and temperature.

For temperature deviation, three severity levels are set (Table 9). The lowest level is when $\Delta \mathrm{T}_{\max }$ is lower than $10 \mathrm{~K}$ with an index of 1 . In the same way, three probability levels are set. The time $\Delta \mathrm{t}_{\mathrm{T}}$ to attain $\Delta \mathrm{T}=10 \mathrm{~K}$ is considered to quantify the probability. These scales are based on the explanations given in part 5.2 and the coloured code chosen is green, yellow and orange as the index increases. 
Dynamic Simulation for Risk Assessment

Table 9: Severity and probability criteria for temperature deviation

\begin{tabular}{|c|c|c|c|c|}
\hline & \multicolumn{3}{|c|}{ Index value } \\
\hline & & 1 & 2 & 3 \\
\hline Severity Criteria & $\Delta \mathrm{T}_{\max }(\mathrm{K})$ & $\Delta \mathrm{T}_{\max }<10$ & $10<\Delta \mathrm{T}_{\max }<40$ & $\Delta \mathrm{T}_{\max }>40$ \\
\hline Probability Criteria & $\Delta \mathrm{t}_{\mathrm{T}}$ to attain $\Delta \mathrm{T}=10 \mathrm{~K}(\mathrm{~min})$ & $\Delta \mathrm{t}_{\mathrm{T}}>30$ & $10<\Delta \mathrm{t}_{\mathrm{T}}<30$ & $\Delta \mathrm{t}_{\mathrm{T}}<10$ \\
\hline
\end{tabular}

For pressure deviation, three severity levels are set (Table 10).

Table 10: Severity and probability criteria for pressure deviation

\begin{tabular}{|c|c|c|c|c|}
\cline { 3 - 5 } \multicolumn{2}{c|}{} & \multicolumn{3}{c|}{ Index value } \\
\cline { 3 - 5 } \multicolumn{2}{c|}{} & 1 & 2 & 3 \\
\hline Severity Criteria & $\Delta \mathrm{P}_{\max }($ bar $)$ & $\Delta \mathrm{P}_{\max }<0.2$ & $0.2<\Delta \mathrm{P}_{\max }<0.8$ & $\Delta \mathrm{P}_{\max }>0.8$ \\
\hline Probability Criteria & $\Delta \mathrm{t}_{\mathrm{P}}$ to attain $\Delta \mathrm{P}=1$ bar (min) & $\Delta \mathrm{t}_{\mathrm{P}}>30$ & $10<\Delta \mathrm{t}_{\mathrm{P}}<30$ & $\Delta \mathrm{t}_{\mathrm{P}}<10$ \\
\hline
\end{tabular}

\section{Normal operating conditions scenario}

In this part, results of the normal conditions simulation are presented.

\subsection{Process control and blocks sizing}

The control strategy is set up. A heating temperature controller is used, after the feeding step. It is programmed to rise the temperature to $333 \mathrm{~K}$ in order to start the reaction. A cooling temperature controller is activated at the beginning of the dosing step. The pressure is controlled to be kept at atmospheric pressure. The control parameters are summarized in Table 11. A PSV is sized and implemented into the process. The main parameters are listed in Table 12.

Table 11: Control parameters of the reactor

\begin{tabular}{|c|c|c|c|c|c|c|c|}
\hline \multirow[t]{2}{*}{ Control } & \multirow[t]{2}{*}{ Type } & \multirow[t]{2}{*}{ Action } & \multirow[t]{2}{*}{ Parameter } & \multicolumn{2}{|c|}{ Controlled variable } & \multicolumn{2}{|c|}{ Manipulated variable } \\
\hline & & & & Set Point & Range & Nominal value & Range \\
\hline \multirow{2}{*}{$\begin{array}{c}\text { Reactor } \\
\text { temperature (First } \\
\text { loop for cooling) }\end{array}$} & \multirow[t]{2}{*}{ PI } & \multirow[t]{2}{*}{ Direct } & \multirow[t]{2}{*}{$\begin{array}{l}\text { Gain: } 2 \% \text { Int. } \\
\text { time: } 4 \text { min }\end{array}$} & \multicolumn{2}{|c|}{ Temperature (K) } & \multicolumn{2}{|c|}{$\begin{array}{l}\text { Cooling fluid flowrate } \\
\qquad(\mathrm{kg} / \mathrm{hr})\end{array}$} \\
\hline & & & & 333 & $0-200$ & 115 & $0-345$ \\
\hline \multirow{2}{*}{$\begin{array}{c}\text { Reactor } \\
\text { temperature } \\
\text { (Second loop for } \\
\text { heating) }\end{array}$} & \multirow[t]{2}{*}{ PI } & \multirow[t]{2}{*}{ Direct } & \multirow[t]{2}{*}{$\begin{array}{c}\text { Gain: } 2 \% \text { Int. } \\
\text { time: } 4 \mathrm{~min}\end{array}$} & \multicolumn{2}{|c|}{ Temperature (K) } & \multicolumn{2}{|c|}{$\begin{array}{l}\text { Heating fluid flowrate } \\
\qquad(\mathrm{kg} / \mathrm{hr})\end{array}$} \\
\hline & & & & $\begin{array}{c}\text { Programmed to } \\
\text { increase from } \\
293 \text { to } 333\end{array}$ & $0-200$ & 60 & $0-60$ \\
\hline \multirow[t]{2}{*}{ Reactor pressure } & \multirow[t]{2}{*}{ PI } & \multirow[t]{2}{*}{ Direct } & Gain: $20 \%$ & \multicolumn{2}{|c|}{ Pressure (bar) } & \multicolumn{2}{|c|}{ Valve opening (\%) } \\
\hline & & & $\begin{array}{l}\text { Int. time: } \\
12 \mathrm{~min}\end{array}$ & 1,013 & $0-10$ & 0 & $0-100$ \\
\hline
\end{tabular}

Table 12: PSV parameters

\begin{tabular}{|c|c|c|c|c|c|}
\hline $\begin{array}{c}\text { Valid } \\
\text { phases }\end{array}$ & $\begin{array}{l}\text { Diameter } \\
(\mathrm{cm})\end{array}$ & $\begin{array}{c}\text { Valve } \\
\text { characteristic }\end{array}$ & Flow calculation method & $\begin{array}{c}\text { Set } \\
\text { pressure } \\
\text { “P } \mathbf{P}_{\text {set }} \text { (bar) }\end{array}$ & $\begin{array}{c}\text { Reseating } \\
\text { pressure } \\
\text { 'P Preset" (bar) }\end{array}$ \\
\hline $\begin{array}{l}\text { Vapour- } \\
\text { Liquid }\end{array}$ & 5 & Linear & $\begin{array}{c}\text { DIERS Ideal HEM } \\
\text { (Homogeneous thermal } \\
\text { Equilibrium flow Model) }\end{array}$ & 2 & 1.5 \\
\hline
\end{tabular}


A simplified PSV functioning scheme is used in our case study. Fig. 8 illustrates the PSV opening at $\mathrm{P}_{\text {set }}$ and its closing at $\mathrm{P}_{\text {reset }}$ versus the pressure value variation.

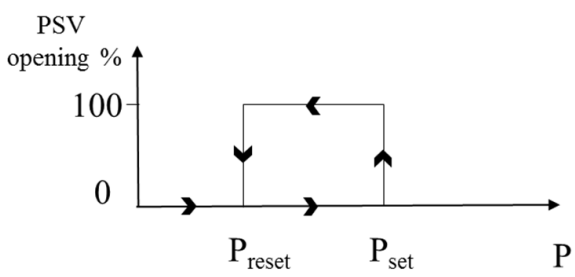

Fig. 8: PSV functioning

\subsection{Dynamic simulation}

The evolution of the temperature and the molar quantities are plotted against the time for a normal operation conditions. The resulting curves are presented Fig. 9. PSV flowrate and pressure profiles are shown in Fig. 10.

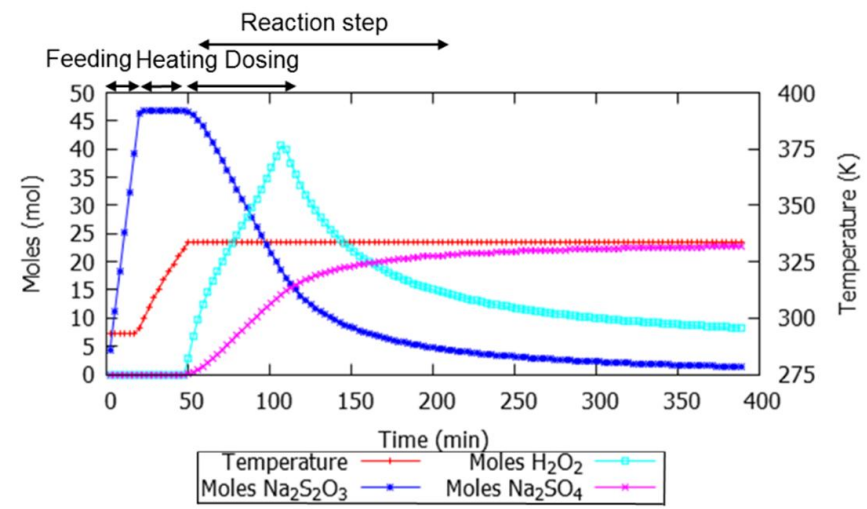

Fig. 9: Temperature and molar quantity evolutions (Normal functioning conditions)

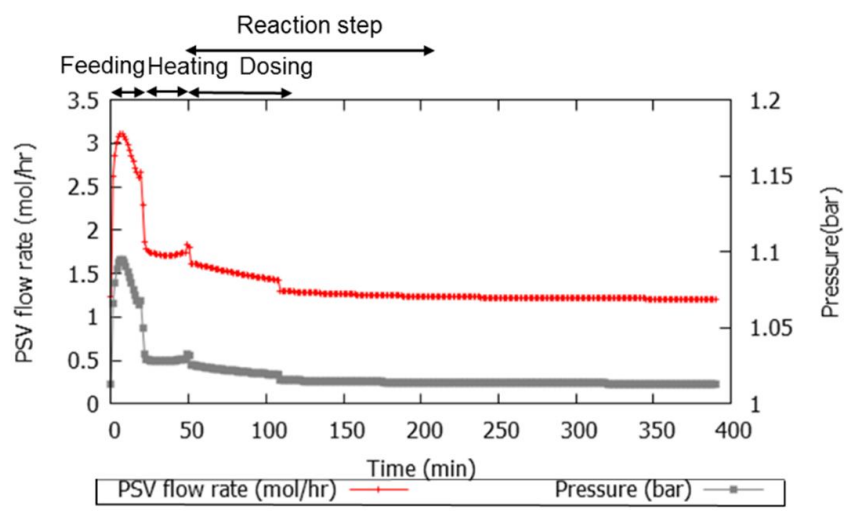

Fig. 10: Pressure and PSV molar flowrate (Normal functioning conditions) 
A $90 \%$ conversion rate of sodium thiosulfate is reached after 204 minutes. The maximum accumulation of hydrogen peroxide (reactant B) in the reactor is $\mathrm{n}_{\max }=41.5$ moles at the end of the dosing step (

Fig. 6). The temperature stabilises at $333 \mathrm{~K}$ as expected. The pressure variations are due to the spare capacity reduction during the feeding and dosing steps (Fig. 10). The atmospheric pressure is guaranteed at the end thanks to the nitrogen input, the pressure controller and the PSV.

\section{Results}

In this part, the simulations of the deviation scenarios previously described are analysed. First, two deviation scenarios (S1 and S12) are presented in full to illustrate the risk quantification method applied to the previously defined deviation scenarios. Then, risk matrices are given. Finally, the global database is presented and a case with an added safety barrier is illustrated.

\subsection{Dynamic simulation of a deviation scenario}

\subsubsection{Complete loss of cooling (scenario S1)}

The first scenario considers a complete loss of cooling at the beginning of the hydrogen peroxide dosing step (reactant B), i.e. at $t=48$ min. Fig. 11 and Fig. 12 present its consequences.

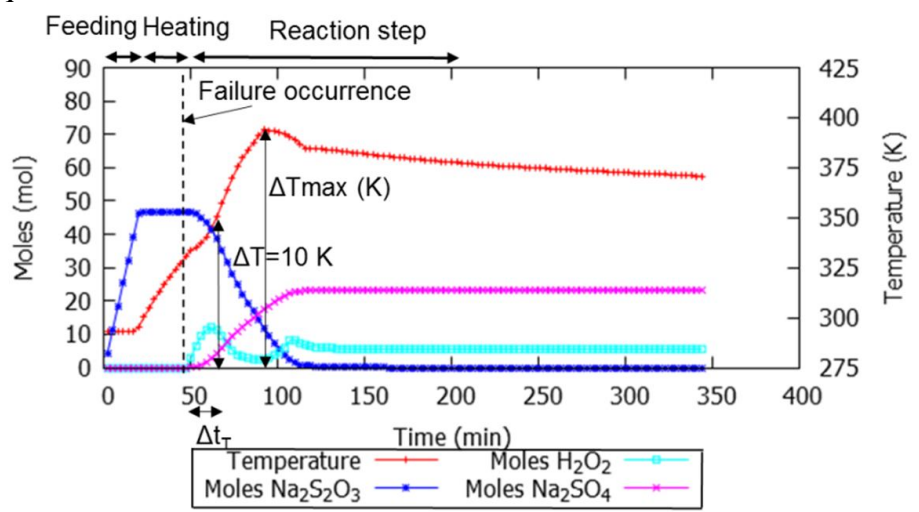

Fig. 11: Temperature and molar quantity evolutions in a semi-batch reactor (scenario 1)

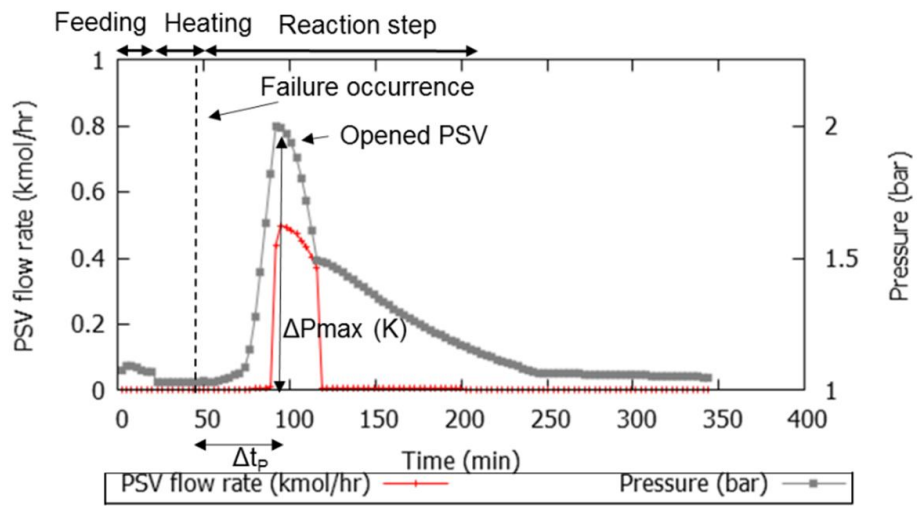


Fig. 12: Pressure and PSV molar flowrate (scenario 1)

Regarding the evolution of molar quantity and temperature (Fig. 1):

- At $\mathrm{t}=61 \mathrm{~min}$, the maximum accumulation of $\mathrm{H}_{2} \mathrm{O}_{2}$ is reached $\left(\mathrm{n}_{\text {max }}^{\prime}=12\right.$ moles $)$;

- The temperature rises by $10 \mathrm{~K}(\Delta \mathrm{T}=10 \mathrm{~K})$ after $\Delta \mathrm{t}_{\mathrm{T}}=13 \mathrm{~min}$. The corresponding probability index is consequently 2 ;

- The MTSR is equal to $394 \mathrm{~K}$ and is reached at $\mathrm{t}=94.8 \mathrm{~min}\left(\Delta \mathrm{t}_{\mathrm{Tmax}}=\right.$ $44 \mathrm{~min})$. This is equivalent to an augmentation of the temperature of $61 \mathrm{~K}$ since the beginning of the cooling loss $\left(\Delta \mathrm{T}_{\max }=61 \mathrm{~K}\right)$. The corresponding severity index is consequently 3 ;

- The temperature risk level is thus equal to 6 .

Because of the rise in temperature, the reaction rate accelerates, starting from the failure occurrence date $(\mathrm{t}=48 \mathrm{~min})$. After the MTSR is reached $(\mathrm{t}=94.8 \mathrm{~min})$, temperature decreases, hence the reaction rate. Then the consumption of $\mathrm{H}_{2} \mathrm{O}_{2}$ decreases and we obtain a second peak of $\mathrm{H}_{2} \mathrm{O}_{2}$ molar quantity in the reactor (Fig. 11).

Regarding the evolution of pressure (Fig. 12):

- At $\mathrm{t}=94.8 \mathrm{~min}$, in parallel to the peak of temperature, a peak of pressure is reached $\left(\Delta \mathrm{P}_{\max }=2 \mathrm{bar}, \Delta \mathrm{t}_{\mathrm{Pmax}}=50.8 \mathrm{~min}\right)$. Accordingly to our initial configurations, the PSV opens and the pressure starts to decrease. Consequently, the corresponding pressure severity index is 3 and the corresponding pressure probability index is 1 ;

- The pressure risk level is thus equal to 3.

When the pressure decreases to 1.5 bar, the PSV closes.

\subsubsection{More concentration of reactant B and contamination of reactant B (scenario S12)}

This scenario is the combination of the scenario S7 and S8 (part 5.1). The operator has forgotten to dilute the hydrogen peroxide and there is a contamination by ferric ions $\left(\mathrm{Fe}^{3+}\right)$. Fig. 13 and Fig. 14 present its consequences:

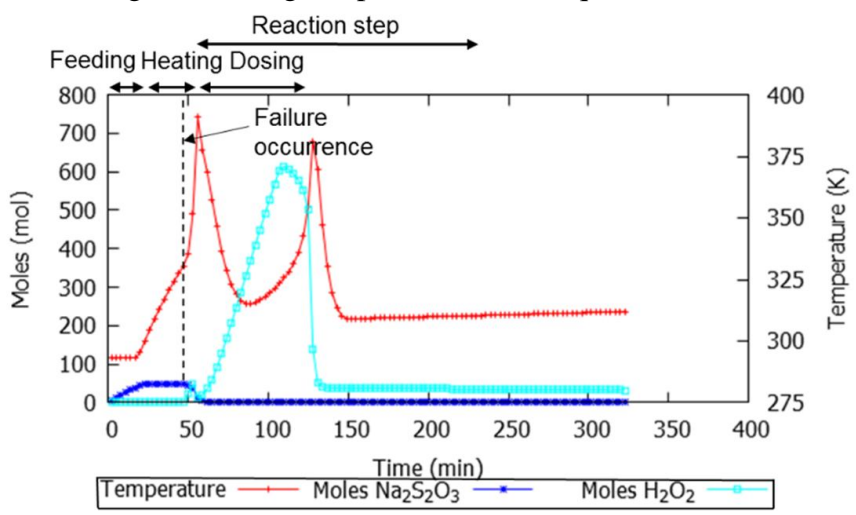

Fig. 13: Temperature and molar quantity evolutions in a semi-batch reactor (scenario 12) 


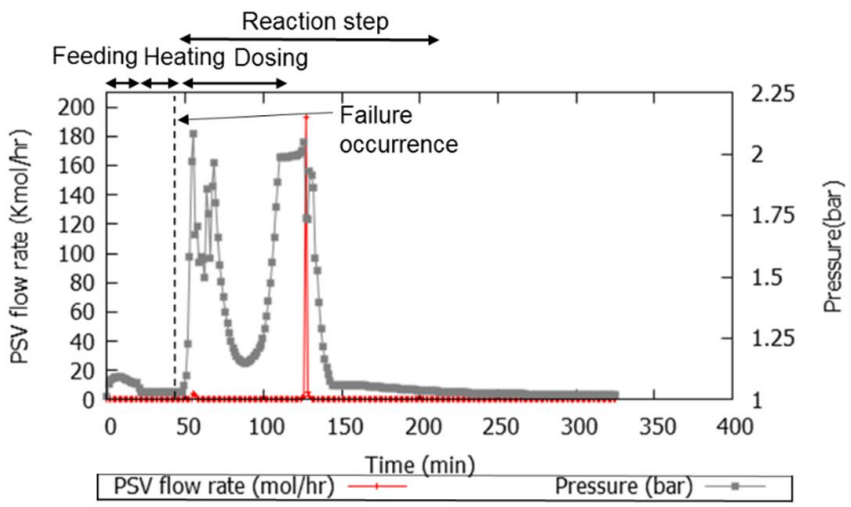

Fig. 14: Pressure and PSV molar flowrate (scenario 7)

A $90 \%$ conversion rate of sodium thiosulfate is reached after 60 minutes, the deviation results in a higher reaction rate. In addition, the accumulated hydrogen peroxide (reactant B) decomposes. The PSV has an oscillatory behaviour (Fig. 14) as it is not sized based on this hazardous case scenario. For scenario S12, both temperature and pressure risk level indices are equal to 9.

\subsubsection{Database}

The results are summarized in Table 13. The following data are given:

- the scenario identification number

- the studied deviation description

- the maximum temperature rise $\Delta \mathrm{T}_{\max }$

- the maximum pressure rise $\Delta \mathrm{P}_{\max }$

- the time duration $\Delta \mathrm{t}_{\mathrm{T}}$ it takes to reach $\Delta \mathrm{T}=10 \mathrm{~K}$

- the time duration $\Delta \mathrm{t}_{\mathrm{P}}$ it takes to reach $\Delta \mathrm{P}=1$ bar

- the conversion of sodium thiosulphate at $\mathrm{t}=204 \mathrm{~min}$

- the relative change "R" of the maximum accumulation of hydrogen peroxide in a deviation scenario " $n$ ' max" from the maximum accumulation of hydrogen peroxide in normal operating conditions " $\mathrm{n}_{\max }$ ", which is calculated as follows:

$$
R=\frac{n_{\max }^{\prime}-n_{\max }}{n_{\max }}
$$


Table 13: Quantitative HAZOP database

\begin{tabular}{|c|c|c|c|c|c|c|c|}
\hline $\begin{array}{c}\text { Scenario } \\
\text { number }\end{array}$ & Deviation & $\Delta T_{\max }$ & $\Delta \mathbf{P}_{\max }$ & $\begin{array}{c}\Delta \mathbf{t}_{\mathrm{T}} \text { to } \\
\text { attain } \\
\Delta \mathrm{T}=\mathbf{1 0} \\
\mathrm{K}(\mathrm{min})\end{array}$ & $\begin{array}{c}\Delta t_{P} \text { to attain } \\
\Delta P=1 \text { bar } \\
\quad(\text { min })\end{array}$ & $\begin{array}{c}\text { Conversi } \\
\text { on at } \\
t=204 \\
\min (\%)\end{array}$ & $\begin{array}{l}\text { R (\%) } \\
\text { Cf. } \\
\text { equation } \\
\text { (10) }\end{array}$ \\
\hline & Normal conditions & 1 & 0.1 & _ & - & $90 \%$ & $0 \%$ \\
\hline S1 & 1 No cooling & 61 & 1.0 & 13.2 & 43.8 & $100 \%$ & $-44 \%$ \\
\hline $\mathrm{S} 2$ & \multirow[t]{3}{*}{2 Less cooling } & 10 & 0,1 & 16,8 & - & $96 \%$ & $-26 \%$ \\
\hline S3 & & 30 & 0.1 & 13.2 & - & $100 \%$ & $-58 \%$ \\
\hline $\mathrm{S} 4$ & & 61 & 1.0 & 13.8 & 47.4 & $100 \%$ & $-69 \%$ \\
\hline S5 & 3 More cooling & 1 & 0.1 & - & - & $21 \%$ & $123 \%$ \\
\hline S6 & $\begin{array}{l}4 \text { More concentration } \\
\text { (reactant B) }\end{array}$ & 1 & 0.1 & - & - & $100 \%$ & $175 \%$ \\
\hline S7 & $\begin{array}{l}4 \text { More concentration } \\
\text { (reactant B) }\end{array}$ & 3 & 0.1 & - & - & $100 \%$ & $1715 \%$ \\
\hline S8 & 5 Product contamination & 1 & 0.6 & _ & - & $0 \%$ & $-96 \%$ \\
\hline S9 & $\begin{array}{l}6 \text { No cooling and } \\
\text { undersized PSV }\end{array}$ & 63 & 1.2 & 12.6 & 43.8 & $100 \%$ & $-44 \%$ \\
\hline S10 & $\begin{array}{l}7 \text { No cooling and } \\
\text { undersized PSV }\end{array}$ & 63 & 1.2 & 12.6 & 43.8 & $100 \%$ & $-44 \%$ \\
\hline S11 & $\begin{array}{l}8 \text { More cooling and } \\
\text { temperature returns to } \\
\text { operating value at } \mathrm{t}=108 \\
\text { min }\end{array}$ & 7.6 & 0.1 & - & - & $73 \%$ & $113 \%$ \\
\hline S12 & $\begin{array}{l}9 \text { More concentration and } \\
\text { contamination (reactant B) }\end{array}$ & 59 & 1.0 & 3.6 & 6.6 & $100 \%$ & $1388 \%$ \\
\hline
\end{tabular}

\subsubsection{Risk matrices}

The simulation results allow the quantification, in terms of temperature and pressure, of the concurrency and severity of the deviation scenarios consequences. Table 14 and Table 15 give a global view on the scenarios risk levels. The scenarios S1 to S12 are ranked.

\begin{tabular}{|c|c|c|c|c|}
\hline & \multicolumn{3}{|c|}{ Probability } \\
\hline & & 1 & 2 & 3 \\
\hline \multirow{3}{*}{$\begin{array}{l}\overrightarrow{0} \\
\vec{D} \\
\vec{D}\end{array}$} & 3 & & S1 S4 S9 S10 & S12 \\
\hline & 2 & & S3 & \\
\hline & 1 & S5 S6 S7 S8 S11 & $\mathbf{S 2}$ & \\
\hline
\end{tabular}

\begin{tabular}{|c|c|c|c|c|}
\hline & \multicolumn{3}{|c|}{ Probability } \\
\hline & & 1 & 2 & 3 \\
\hline \multirow{3}{*}{$\begin{array}{l}\overrightarrow{\bar{D}} \\
\vec{\nu} \\
\tilde{\omega}\end{array}$} & 3 & S1 S4 & & S12 \\
\hline & 2 & S8 S9 S10 & & \\
\hline & 1 & $\begin{array}{c}\text { S2 S3 S5 S6 S7 } \\
\text { S11 }\end{array}$ & & \\
\hline
\end{tabular}

Some scenarios can be eliminated because of their low risk level. On the contrary, the scenarios S1, S4, S9, S10 and S12 have medium or high-risk levels (Table 14 and Table 
15). Further investigations are to be made in order to determine which safety barriers can be added to lower their risk levels.

7.2. Risk level quantification and additional safety barriers

In this section, the possibility of implementing supplementary safety barriers is discussed. Based on the previous results, the ALARP (As Low As Reasonably Possible) concept can be applied in order to lower the risk level by including adequate safety barriers for each scenario. Temperature and pressure alarms (part 5.2) alert the operator once the threshold values are attained. The operator then intervenes to stop the deviation effects. In previous work (Berdouzi et al., 2016), additional automatic dosing interruption is programmed in case of cooling loss. The interruption of dosing would prevent such high level of temperature and pressure, lowering the severity and probability of a deviation. With this in mind, it would lower the global risk level of the scenarios S1, S4, S9 and S10.

Regarding S12, a stabilizer can be used to prevent hydrogen peroxide $\left(\mathrm{H}_{2} \mathrm{O}_{2}\right)$ decomposition. These safety barriers can be added to the simulation in order to validate their proper functioning and to appreciate the risk level decrease.

For this case study, we choose to present an SIS, which interrupts the dosing when the temperature is greater than a defined threshold value. This SIS is programmed within the simulation to switch the dosed reactant $\left(\mathrm{H}_{2} \mathrm{O}_{2}\right)$ flowrate to zero when the reactor temperature exceeds a predefined value.

Numerical data of the previously studied scenario S1 are compared with the data from the scenario S13 simulation. The only difference between these two simulations is the addition of the dosing automatic interruption system. S13 is described as follows:

- Scenario S13: "MORE temperature in the reactor due to complete loss of cooling at time corresponding to reactant cooling start $(\mathrm{t}=48 \mathrm{~min})$ and addition of safety barrier permitting the dosing automatic interruption (when T reaches $343 \mathrm{~K}$ )"

Fig. 15 and Fig. 16 present this comparison, with a focus on the temperature, the $\mathrm{Na}_{2} \mathrm{~S}_{2} \mathrm{O}_{3}$ molar quantity, and the pressure:

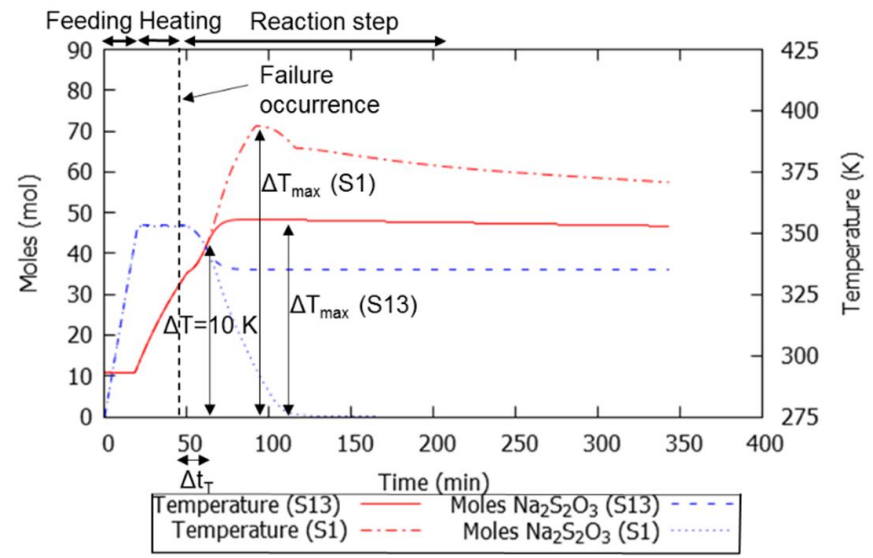

Fig. 15: Temperature and molar quantity evolutions in a semi-batch reactor (scenario S1 and S13) 


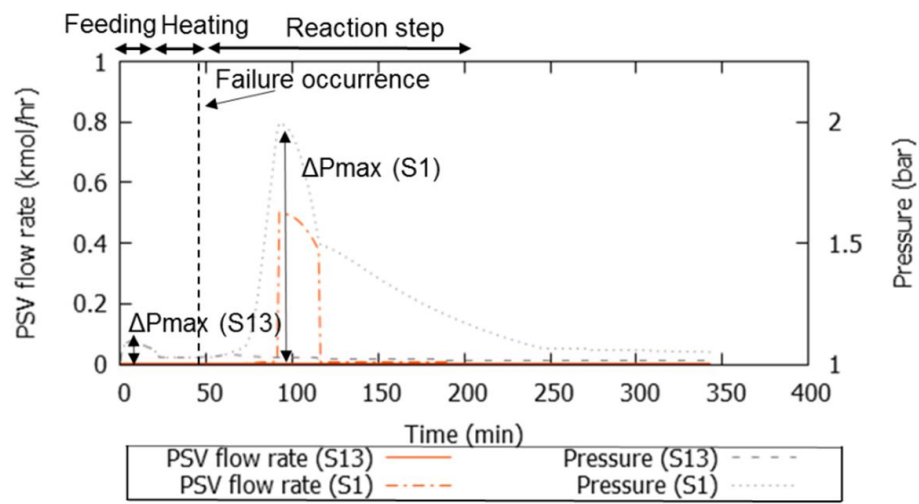

Fig. 16: Pressure and PSV molar flowrate (scenario S1 and S13)

Fig. 15 demonstrates that during the scenario $\mathrm{S} 13$, as $\mathrm{H}_{2} \mathrm{O}_{2}$ dosing is interrupted by the SIS, $\mathrm{Na}_{2} \mathrm{~S}_{2} \mathrm{O}_{3}$ conversion is consequently stopped (dashed blue line). Both figures show that with the additional barrier, the risk level is decreased for temperature and pressure. For the scenario S13:

- the maximum temperature is $\Delta \mathrm{T}_{\max }=22 \mathrm{~K}$ (severity level is 2) and the $\Delta \mathrm{T}=10 \mathrm{~K}$ takes $\Delta \mathrm{t}_{\mathrm{T}}=13$ minutes to be reached (probability level is 2);

- the maximum overpressure is $\Delta \mathrm{P}_{\max }=0.1$ bar (severity level is 1 ) and the PSV stay closed (probability level is 1 ).

Concisely, the temperature risk level is decreased from the value of 6 for scenario S1 (high/orange) to the value of 4 (medium/yellow) for scenario S13, and the pressure risk level decreases from a value of 3 for scenario S1 (medium/yellow), to the value of 1 for scenario S13 (low/green). The risk level comparison is shown in Table 16.

Table 16: Risk level values for S1 and S13

\begin{tabular}{|l|c|c|}
\cline { 2 - 3 } \multicolumn{1}{c|}{} & \multicolumn{2}{c|}{ Deviation scenario } \\
\cline { 2 - 3 } \multicolumn{1}{c|}{} & S1 & S13 \\
\hline Temperature risk level & 6 & 4 \\
\hline Pressure risk level & 3 & 1 \\
\hline
\end{tabular}

\section{Conclusion and perspectives}

In this paper, a process safety method is developed using HAZOP classical framework combined with deviation scenarios dynamic simulation and risk matrix tool. Aspen Plus Dynamics is used to simulate the scenarios and quantify the deviations effects. A case study is chosen to illustrate the methodology application. Experimental data permit evaluation of the system stability. Both principal and decomposition reactions are implemented in the reactor model. Once deviation scenarios are simulated, the risk levels are calculated. This allows ranking of the scenarios and appreciation of the risk acceptability. Some of the deviations with two successive or simultaneous deviations scenarios brought attention to the need of a further investigation. The dynamic simulation allows quantification of their effects. When the risk level of a deviation scenario is unacceptable, additional safety barriers are added and validated. The threshold values used for the severity and probability levels are defined in accordance with the studied process kinetics, operating conditions and safety constraints. In the future, this 
methodology will be applied to more complex processes to investigate deviation propagation along the process.

\begin{tabular}{|c|c|c|}
\hline Nomenclature & & \\
\hline $\mathrm{E}_{\mathrm{a}}$ & Activation energy & J.mol ${ }^{-1}$ \\
\hline $\mathrm{E}_{\mathrm{a}}^{\prime}$ & Decomposition reaction activation energy & J.mol ${ }^{-1}$ \\
\hline $\mathrm{k}_{0}$ & Pre-exponential factor & $\mathrm{m}^{3} \cdot \mathrm{mol}^{-1} \cdot \mathrm{s}^{-1}$ \\
\hline $\mathrm{k}_{0}{ }_{0}$ & $\begin{array}{l}\text { Decomposition reaction pre-exponential } \\
\text { factor }\end{array}$ & $\mathrm{m}^{3} \cdot \mathrm{mol}^{-1} \cdot \mathrm{s}^{-1}$ \\
\hline $\mathrm{k}_{\mathrm{f}}$ & $\begin{array}{l}\text { Multiplicative decomposition reaction } \\
\text { coefficient }\end{array}$ & \\
\hline $\mathrm{n}_{\max }$ & $\begin{array}{l}\text { Maximum value of } \mathrm{H}_{2} \mathrm{O}_{2} \text { accumulation in } \\
\text { normal operating conditions }\end{array}$ & mol \\
\hline$n_{\text {max }}^{\prime}$ & $\begin{array}{l}\text { Maximum value of } \mathrm{H}_{2} \mathrm{O}_{2} \text { accumulation in } \\
\text { deviation senarios }\end{array}$ & mol \\
\hline $\mathrm{P} 1$ & Sample pressure & barg \\
\hline $\mathrm{P} 2$ & Containement vessel pressure & barg \\
\hline $\mathrm{P}_{\mathrm{AH}}$ & Alarm high triggering pressure value & bar \\
\hline $\mathrm{P}_{\mathrm{P}}$ & Normal condition process pressure & bar \\
\hline$P_{\text {set }}$ & Pressure safety valve setpressure & bar \\
\hline $\mathrm{P}_{\text {reset }}$ & Pressure safety valve closing pressure & bar \\
\hline $\mathrm{r}$ & Reaction rate & $\mathrm{s}^{-1}$ \\
\hline r' & Decomposition reaction rate & $\mathrm{s}^{-1}$ \\
\hline $\mathrm{T} 1$ & Sample temperature & ${ }^{\circ} \mathrm{C}$ \\
\hline $\mathrm{T} 2$ & Containement vessel temperature & ${ }^{\circ} \mathrm{C}$ \\
\hline $\mathrm{T}_{\mathrm{AH}}$ & Alarm high triggering temperature value & $\mathrm{K}$ \\
\hline $\mathrm{T}_{\mathrm{B}}$ & Bouling point & $\mathrm{K}$ \\
\hline $\mathrm{T}_{\mathrm{P}}$ & Normal condition process temperature & $\mathrm{K}$ \\
\hline$\Delta \mathrm{H}_{\mathrm{r}}$ & Reaction enthalpy & $\mathrm{kJ} \cdot \mathrm{mol}^{-1}$ \\
\hline$\Delta \mathrm{H}_{\mathrm{r}}^{\prime}$ & Decomposition reaction enthalpy & $\mathrm{kJ} \cdot \mathrm{mol}^{-1}$ \\
\hline$\Delta \mathrm{T}_{\mathrm{ad}}$ & Adiabatic temperature rise & $\mathrm{K}$ \\
\hline
\end{tabular}




\section{References}

API Standard 520, 2014. Sizing, Selection, and Installation of Pressure-relieving Devices. API Standard 521, 2014. Pressure-relieving and Depressuring Systems.

Aspen Plus Dynamics, 2017. URL https://esupport.aspentech.com/

Baybutt, P., 2015a. A critique of the Hazard and Operability (HAZOP) study. J. Loss Prev. Process Ind. 33, 52-58. doi:10.1016/j.jlp.2014.11.010

Baybutt, P., 2015b. Calibration of risk matrices for process safety. J. Loss Prev. Process Ind. 38, 163-168. doi:10.1016/j.jlp.2015.09.010

Benaissa, W., Elgue, S., Carson, D., Gabas, N., Cabassud, M., 2008. Dynamic Behaviour of a Continuous Heat Exchanger / Reactor after Flow Failure. Int. J. Chem. React. Eng. 6, 1-21.

Benkouider, A.M., Kessas, R., Yahiaoui, A., Buvat, J.C., Guella, S., 2012. A hybrid approach to faults detection and diagnosis in batch and semi-batch reactors by using EKF and neural network classifier. J. Loss Prev. Process Ind. 25, 694-702. doi:10.1016/j.jlp.2012.03.005

Berdouzi, F., Olivier-Maget, N., Gabas, N., 2016. Using Dynamic Simulation for Risk Assessment: Application to an Exothermic Reaction. Comput. Aided Chem. Eng. 38, 1563-1568. doi:https://doi.org/10.1016/B978-0-444-63428-3.50265-4

Chetouani, Y., Mouhab, N., Cosmao, J.M., Estel, L., 2003. Dynamic model-based technique for detecting faults in a chemical reactor. Process Saf. Prog. 22, 183-190. doi:10.1002/prs.680220308

Duijm, N.J., 2015. Recommendations on the use and design of risk matrices. Saf. Sci. 76, 21-31. doi:10.1016/j.ssci.2015.02.014

Eizenberg, S., Shacham, M., Brauner, N., 2006a. Combining HAZOP with dynamic simulationApplications for safety education. J. Loss Prev. Process Ind. 19, 754-761. doi:10.1016/j.jlp.2006.07.002

Eizenberg, S., Shachama, M., Braunerb, N., 2006b. Combining HAZOP with dynamic process model development for safety analysis. Comput. Aided Chem. Eng. 389-394. doi:10.1016/S1570-7946(06)80077-5

Etchells, J., Wilday, J., 1998. Workbook for chemical reactor relief system sizing, Crown. ed.

European Chemical Industry Coucil CEFIC, 2012. Bulk Storage, Peroxygens Hydrogen Peroxide $1-50$.

French Environment Energy and the Sea Ministry, 2017. ARIA data bank. URL http://www.aria.developpement-durable.gouv.fr/

Fuentes-Bargues, J.L., Gonzàlez-Gaya, C., Gonzàlez-Cruz, M.C., Cabrelles-Ramirez, V., 2016. Risk assessment of a compound feed process based on HAZOP analysis and linguistic terms. J. Loss Prev. Process Ind. 44, 44-52. doi:10.1016/j.jlp.2016.08.019

Galante, E., Bordalo, D., Nobrega, M., 2014. Risk Assessment Methodology : Quantitative HazOp 3, 31-36. doi:10.5923/j.safety.20140302.01

IEC, 2016. Hazard and operability studies (HAZOP studies) - Application guide Études IEC 61882:2016.

ISO 31010, 2010. Risk management - risk assessment techniques. 2010E, IEC/ISO 31010:2010.

Jain, P., Pasman, H.J., Waldram, S.P., Rogers, W.J., Mannan, M.S., 2016. Did we learn about risk control since Seveso? Yes, we surely did, but is it enough? An historical brief and problem analysis. J. Loss Prev. Process Ind. In press, 1-13. doi:10.1016/j.jlp.2016.09.023

Janosovsky, J., Danko, M., Labovsky, J., Jelemensky, L., 2017. The role of a commercial process simulator in computer aided HAZOP approach 107, 12-21.

Kang, J., Guo, L., 2016. HAZOP analysis based on sensitivity evaluation. Saf. Sci. 88, 26-32. doi:10.1016/j.ssci.2016.04.018

Kletz, T., 1999. HAZOP and HAZAN, Institutio. ed. Warwickshire.

Leung, J.C., Askonas, C.F., Burelbach, J.P., Associates, F., 2000. The versatile Vsp2: a Tool for Adiabatic Thermal Analysis Analysis and Vent Sizing Applications. North Am. Therm. Anal. Soc. 28, 2-7.

Lou, H.H., Chandrasekaran, J., Smith, R. a., 2006. Large-scale dynamic simulation for security assessment of an ethylene oxide manufacturing process. Comput. Chem. Eng. 30, 11021118. doi:10.1016/j.compchemeng.2006.02.011

Lu, L., Liang, W., Zhang, L., Zhang, H., Lu, Z., Shan, J., 2015. A comprehensive risk evaluation 
method for natural gas pipelines by combining a risk matrix with a bow-tie model. J. Nat. Gas Sci. Eng. 25, 124-133. doi:10.1016/j.jngse.2015.04.029

Luyben, W., 2002. Plantwide Dynamic Simulators in Chemical Processing and Control, Marcel Dek. ed. CRC Press.

Luyben, W.L., 2012. Use of dynamic simulation for reactor safety analysis. Comput. Chem. Eng. 40, 97-109. doi:10.1016/j.compchemeng.2012.02.013

Marhavilas, P.K., Koulouriotis, D., Gemeni, V., 2011. Risk analysis and assessment methodologies in the work sites: On a review, classification and comparative study of the scientific literature of the period 2000-2009. J. Loss Prev. Process Ind. 24, 477-523. doi:10.1016/j.jlp.2011.03.004

Markos, J., Jelemensky, L., MOLNAR, A., 2005. Some considerations for safety analysis of chemical reactors. Chem. Eng. Res. Des. 83, 167-176.

Mkhida, A., Thiriet, J.M., Aubry, J.F., 2014. Integration of intelligent sensors in Safety Instrumented Systems (SIS). Process Saf. Environ. Prot. 92, 142-149. doi:10.1016/j.psep.2013.01.001

NF EN ISO 4126, 2016. Safety devices for protection against excessive pressure.

Ni, H., Chen, A., Chen, N., 2010. Some extensions on risk matrix approach. Saf. Sci. 48, 1269 1278. doi:10.1016/j.ssci.2010.04.005

Ni, L., Mebarki, A., Jiang, J., Zhang, M., Dou, Z., 2016. Semi-batch reactors: Thermal runaway risk. J. Loss Prev. Process Ind. 43, 559-566. doi:10.1016/j.jlp.2016.07.024

Olivier-maget, N., Hetreux, G., 2015. Fault detection and diagnosis using a hybrid dynamic simulator :application to industrial risk prevention. J. Eur. des Systèmes Autom. 49, 503535.

Saada, R., Patel, D., Saha, B., 2015. Causes and consequences of thermal runaway incidents Will they ever be avoided? Process Saf. Environ. Prot. 97, 109-115. doi:10.1016/j.psep.2015.02.005

Stoessel, F., 2008. Thermal Safety of Chemical Processes: Risk Assessment and Process Design, Wiley-VCH. ed. Weinheim.

Trujillo, A., Kessler, W.S., Gaither, R., 2015. Common Mistakes When Conducting a HAZOP and How to Avoid Them, Mary Page. ed, Chemical engineering.

Vernières-Hassimi, L., Leveneur, S., 2015. Alternative method to prevent thermal runaway in case of error on operating conditions continuous reactor. Process Saf. Environ. Prot. 98, 365-373. doi:10.1016/j.psep.2015.09.012

Zhang, L., Yu, W.D., Pan, X.H., Fang, J.J., Hua, M., Chen, F.M., Jiang, J.C., 2014. Thermal hazard assessment for synthesis of 3-methylpyridine-N-oxide. J. Loss Prev. Process Ind. 35, 316-320. doi:10.1016/j.jlp.2015.03.022 